\title{
Striving for the Best: How Far Should We Go? Regarding "Impact of Modified TICI 3 versus Modified TICI 2b Reperfusion Score to Predict Good Outcome following Endovascular Therapy"
}

E

ndovascular thrombectomy has become a valuable part of the - treatment of patients with an acute large vessel occlusion in the anterior circulation. High rates of quality reperfusion after endovascular thrombectomy were considered a key element for achieving superior functional outcomes compared with sole medical treatment with IV rtPA. ${ }^{1}$ Because a reperfusion grade of TICI $2 b$ or better has been shown to be a precise and reliable predictor of good functional outcomes, TICI $2 \mathrm{~b}$ and 3 are conventionally considered as "successful reperfusion." In their highly relevant article, Dargazanli et $\mathrm{al}^{3}$ provided further evidence that the outcomes of patients with "complete" (TICI 3) reperfusions are significantly better as opposed to patients with "near complete" (TICI 2b) reperfusions. ${ }^{4}$

These results not only underscore the need for devices that minimize the occurrence of periprocedural thrombus fragmentation potentially accountable for incomplete reperfusions, but also raise the important question of whether interventionalists should strive to achieve TICI 3 reperfusion in cases where TICI $2 b$ is already achieved ("luxury rescue").

Recent studies have suggested that it is technically feasible to reach and recanalize smaller, distal MCA branches when encountered as the primary occlusion site. However, evidence for a clinical benefit of endovascular thrombectomy versus IV rtPA in treating distal occlusions beyond the proximal M2 level is lacking.

Notwithstanding, risk-benefit ratios might differ in the scenario of already achieved TICI $2 \mathrm{~b}$ reperfusions. First, catheter placement is already taking place, which, relatively speaking, diminish the general risks of endovascular treatment (eg, groin he-

http://dx.doi.org/10.3174/ajnr.A5154 matoma). Second, available therapy alternatives are limited when TICI $2 \mathrm{~b}$ reperfusion has already been achieved because the option of administering IV rtPA is usually no longer available.

The study by Dargazanli et $\mathrm{al}^{3}$ supports the notion that a more aggressive treatment approach in striving to achieve TICI 3 reperfusions might be of benefit. Because "luxury rescue" maneuvers (eg, using IA lytics or small stent-retrievers) may inherit the risk of jeopardizing the already achieved benefit of a TICI $2 \mathrm{~b}$ reperfusion, the evaluation of such maneuvers with regard to technical feasibility, safety, and clinical benefit is highly desirable.

Disclosures: Johannes Kaesmacher-UNRELATED: Grants/Grants Pending: KKF (Technical University Munich)*. *Money paid to the institution.

\section{REFERENCES}

1. Manning NW, Chapot R, Meyers PM. Endovascular stroke management: key elements of success. Cerebrovasc Dis 2016;42: 170-77 CrossRef Medline

2. Yoo AJ, Simonsen CZ, Prabhakaran S, et al. Refining angiographic biomarkers of revascularization: improving outcome prediction after intra-arterial therapy. Stroke 2013;44:2509-12 CrossRef Medline

3. Dargazanli C, Consoli A, Barral M, et al. Impact of modified TICI 3 versus modified TICI $2 \mathrm{~b}$ reperfusion score to predict good outcome following endovascular therapy. AJNR Am J Neuroradiol 2017;38: 90-96 CrossRef Medline

4. Kleine JF, Wunderlich S, Zimmer C, et al. Time to redefine success? TICI 3 versus TICI $2 \mathrm{~b}$ recanalization in middle cerebral artery occlusion treated with thrombectomy. J Neurointerv Surg 2017;9:117-21 CrossRef Medline

(D). Kaesmacher Department of Diagnostic and Interventional Neuroradiology Klinikum Rechts der Isar Technical University Munich Munich, Germany 